\title{
Verification of the Reliability of a Superconducting Flywheel Energy Storage System and Its Application to the Railway System
}

\author{
Tomohisa YAMASHITA \\ Maglev Systems Technology Division \\ Masafumi OGATA \\ Hitoshi MATSUE \\ Yoshiki MIYAZAKI \\ Cryogenic Systems Laboratory, Maglev Systems Technology Division \\ Motohiko SUGINO \\ Central Japan Railway Company \\ Ken NAGASHIMA \\ Maglev Systems Technology Division

\begin{abstract}
Flywheel energy storage systems (FESS) can moderate fluctuations in output from renewable energy such as solar photovoltaic power or wind power generation systems. A FESS was developed as a joint project involving five enterprises with financial support from the New Energy and Industrial Technology Development Organization (NEDO). The key technology used in FESS is the high temperature superconducting magnetic bearing (SMB). It consists of high temperature superconducting coils used for its stator and high temperature superconducting bulks used for its rotor. A FESS prototype was installed in the power plant, and its charge / discharge of solar photovoltaic power was monitored. Results from tests using a SMB subjected to a levitation time of 3,000 hours, 120 current value increase and decrease cycles and 24 heat cycles verified the reliability of the SMB.
\end{abstract}

Keywords: flywheel energy storage, high temperature superconducting magnetic bearing, solar photovoltaic power, stabilize, renewable energy

\section{Introduction}

Demonstration experiment facilities of superconducting flywheel energy storage system were set up at the photovoltaic power generation station of Komekurayama in Yamanashi Prefecture (Fig. 1), about $100 \mathrm{~km}$ west of Tokyo, in September, 2015, and a demonstration experiment was conducted aimed at verifying the effect of the system to moderate photovoltaic generation electric power output, which is otherwise unstable due to changes in the amount of weather condition [1].

This paper reports on the principles of the experiment and features of the superconducting flywheel energy stor-

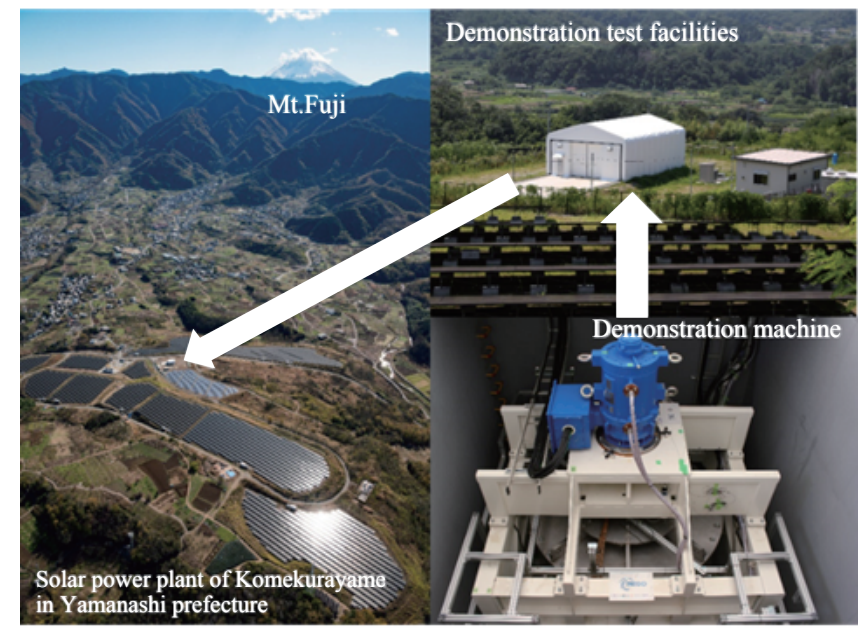

Fig. 1 Overview of demonstration test facilities for the prototype FESS age system equipped with a core superconducting magnetic bearing technology, developed by the Railway Technical Research Institute. This paper also introduces results from demonstration experiments conducted at the mega photovoltaic plant of Komekurayama and results of the reliability verification test on the FESS which used the Komekurayama prototype. Further a way of thinking of development of application of this new mechanical electrical energy storage system to electric railway is described based on its obtained knowledge.

\section{Superconducting flywheel energy storage system (FESS)}

Superconducting flywheel energy storage system (FESS) is a system which converts the electric energy to the kinetic energy by making a built-in hollow-cylindrical shape (flywheel) revolve, saves the converted energy, and can convert the kinetic energy to the electric power again as the need arises.

FESS is the mechanical electric energy storage system to support a flywheel without contact, by a superconducting magnetic bearing (SMB) which makes use of the strong magnetic repulsive force. The system need not repeat battery charging and discharging different from a secondary cell.

With respect to the countermeasure system against lapse of regenerative electric power of electric railway vehicle and the countermeasure system for stabilizing the output of electrical energy generating system making use of renewable energy such as the photovoltaic and the wind power generation, the systems must cope with the battery 
charging and discharging cycles of more than from several hundreds of thousands of times to several millions of times per 20 years of the operating life of the system.

In this regard FESS can be one of the choices for the countermeasure systems.

Development of FESS has been promoted from the fiscal year 2012 by the cooperation of five organizations of Railway Technical Research Institute, Tokyo, KUBOTEK Corp., Osaka, Furukawa Electric Co., Ltd., Tokyo, Mirapro Co., Ltd., Yamanashi, and Enterprise Bureau of Yamanashi Prefecture for the purpose of stabilizing the solar electric power generation system, with the financial support of the government-affiliated New Energy and Industrial Technology Development Organization (NEDO).

\section{FESS operating principles}

The basic principle and features of a flywheel energy storage system (FESS) are described in this chapter.

The principle of a flywheel energy storage system (FESS) is illustrated in Fig. 2.

When a flywheel with a disk of a mass $\mathrm{M}[\mathrm{kg}]$ and radius $\mathrm{r}[\mathrm{m}]$ rotates with the angular velocity $\omega[\mathrm{rad} / \mathrm{s}]$, the stored energy $\mathrm{E}[\mathrm{J}]$ of the flywheel is given as follows.

$$
E=(1 / 4) M(r \omega)^{2}
$$

Namely the stored energy $\mathrm{E}$ is determined by the design of the flywheel, comprising mass, size and revolution speed.

Stored energy can be charged or discharged as electric energy through the generator motor simply by accelerating or decelerating the revolution speed of the flywheel.

The revolution speed is constantly monitored, which can be used to confirm the remaining amount of the storage energy immediately and stored energy can be reduce to zero simply by suspending rotation of the wheel. These are

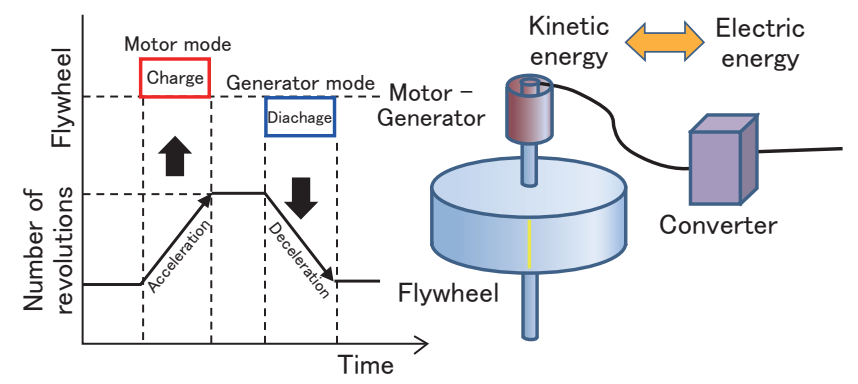

Fig. 2 Schematic representation of FESS operating principles key features which differentiate the FESS from a secondary cell.

Table 1 shows the comparison between FESS and existing systems such as secondary cells and capacitors.

The area connecting output and stored energy (the storage capacity) is limited in secondary cells and capacitors which means that they cannot be freely designed to suit a particular use.

With FESS however, storage energy (the storage capacity) is determined by the mass, size and revolution speed of the flywheel, while charging and discharging of the flywheel are determined by the generator motor settings.

Another defining feature of a FESS therefore, is that the design can be adapted to a purpose because the storage capacity and output can be set independently.

However, in terms of maintainability (conventional type) FESS is inferior to secondary cells and capacitors, as shown in Table 1, because the bearing supporting the flywheel demands periodical large-scale maintenance.

This is a technical obstacle to wider use of flywheel energy storage systems.

This problem however, was settled through the development of the SMB by the Railway Technical Research Institute, which uses strong magnetic repulsion to allow contactless rotation of the flywheel rotate without mechanical loss [2]. The basic structure is shown in Fig. 3.

The relationship between the number of life cycles and depth of discharge (which is the characteristic deterioration relating to the number of battery charging and discharging cycles, and is the index indicating maximum admissible limit for battery charging and discharging) is indicated in Fig. 4.

The secondary cell represented by a lithium-ion battery $(\mathrm{LiB})$ possesses the degradation characteristic that the upper limit of the permission storage energy is restricted to less than $1 /$ several of an early stage, in case the number of repetition of the battery charging and discharging becomes large.

But in case of FESS, the upper limit of the permission storage energy doesn't change even if the number of repetition of the battery charging and discharging is millions of times, because there are no electrochemical reactions like a secondary cell in case of FESS.

It is necessary to cope with more than from several hundreds of thousand times to several millions of times of battery charging and discharging cycle with respect to the countermeasure system against lapse of the regenerative electric power of railway system per 20 years of the operating life.

Taking into consideration the fact that the electrical

Table 1 Comparison with various types of batteries

\begin{tabular}{|l|c|c|c|}
\hline \multicolumn{1}{|c|}{ Item } & $\begin{array}{c}\text { Rechargeable } \\
\text { batteries }\end{array}$ & Capacitor & Flywheel \\
\hline Charge rate & $\triangle$ & $\bigcirc$ & $\bigcirc$ \\
\hline Storage volume & $\bigcirc$ & $\bigcirc$ & $\bigcirc$ \\
\hline Discharge rate & $\triangle$ & $\bigcirc$ & $\bigcirc$ \\
\hline Maintainability & $\bigcirc$ & & $\triangle$ \\
\hline
\end{tabular}




\section{Primary structure}

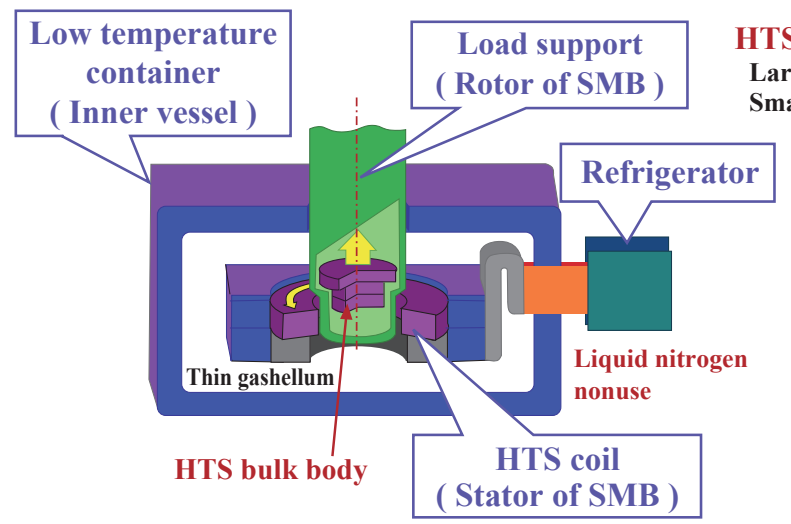

HTS bulk body

Large HTS bulk body ( Dia. $140 \mathrm{~mm}$ ) for levitation : 1 peace

Small HTS bulk body ( Dia. $90 \mathrm{~mm}$ ) for guidance : 2 peaces

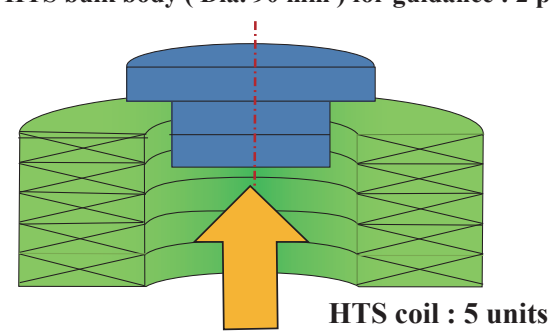

Load : $39.2 \mathrm{kN}$

[Levitation force]

Fig. 3 Primary structure of the SMB

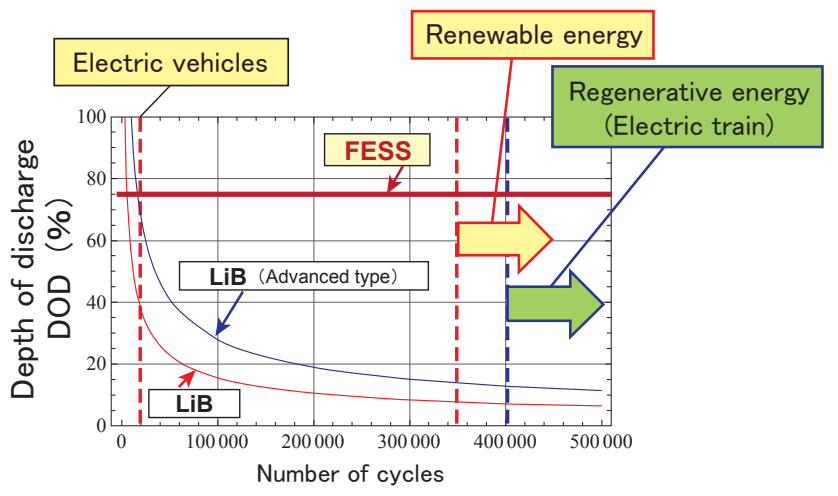

Fig. 4 Comparison with Lithium-ion battery (Operating life)

energy generation system making use of the renewable energy also has to cope with the equal number of times of battery charging and discharging cycle, a test to confirm the effect of stabilizing the output of the solar photovoltaic power was considered to be a preceding inspection test by which the useful data could be obtained for authentic development of application of the countermeasure to the railway system in the future.

\section{Development and promotion through a common public private project}

Research and development into FESS started as the study on application of the superconducting technology developed as a part of MAGLEV technology by Railway Technical Research Institute to an ordinary railway widely.

Because the FESS technology can be also applicable to stabilization of the generated output of the renewable energy power plant which is used for "energy storage of the short cycle and of the numerous number of times," and also can be applicable to the countermeasure against lapse of regenerative electric power of railway system, Railway Technical Research Institute considered the various tests of FESS as the preceding inspections for these technologies.

On the other hand, Yamanashi Prefecture possesses an independent hydroelectric plant and is bringing sale of electric power into effect. Accordingly, it considered Electric Power Development as an important theme and established the policy to introduce aggressively photovoltaic generation among the renewable energy and was promoting construction of a photovoltaic generation plant of 10 MW at Komekurayama jointly with Tokyo Electric Power.

Thus the prefecture was seeking the charge system of electric power useful for moderation of the output of the generated electric power.

Against this background, a technological cooperative agreement was concluded between the Railway Technical Research Institute and Yamanashi Prefecture in 2011, to advance development of the electric power charge system by utilizing superconducting technology [3].

Five bodies namely Yamanashi Prefecture, the Railway Technical Research Institute and 3 private enterprises (KUBOTEK, Furukawa Electric and Mirapro) applied for the "safety and low-cost large-scale charge system technical development" subsidy from NEDO in the fiscal year 2012, and set up a technological development consortium coordinated by the Railway Technical Research Institute.

The development of a prototype FESS and demonstration experiments at the photovoltaic power plant in Komekurayama in Yamanashi Prefecture therefore began under the impetus of this public private consortium.

\section{The feature of the FESS prototype}

The purpose of the demonstration tests was to verify the moderating effect of connecting a FESS prototype to a photovoltaic power plant with an output of $1 \mathrm{MW}$ selected from among the solar photovoltaic power plants in Komekurayama, Yamanashi Prefecture.

An example of power variation in output from a photovoltaic power plant with an output of $1 \mathrm{MW}$ in Komekurayama, is shown in Fig. 5.

Figure 5 shows that power output from the photovoltaic plant fluctuates with the amount of sunshine which varies between sunrise and sunset. Fluctuations are roughly $300 \mathrm{~kW}$, as shown by the dashed line. The prototype output was therefore set at $300 \mathrm{~kW}$.

The storage capacity of the flywheel was set to 100 $\mathrm{kWh}$ according to NEDO specifications $(300 \mathrm{~kW}$ and 20 


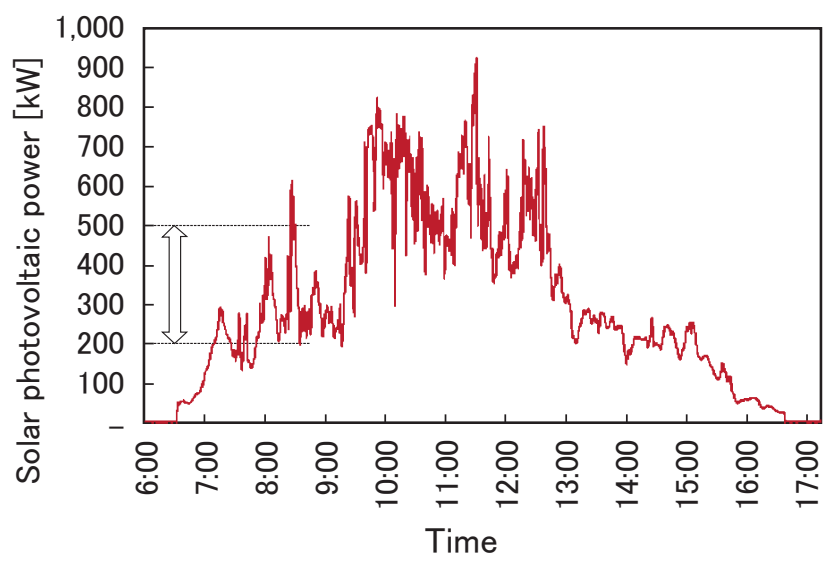

Fig. 5 Characteristics of solar PV power

Table 2 Specifications of FESS

\begin{tabular}{|l|l|}
\hline Output power & $300 \mathrm{~kW}$ \\
\hline Storage capacity & $100 \mathrm{kWh}$ \\
\hline Maximum revolution speed & $6000 \mathrm{~min}^{-1}$ \\
\hline $\begin{array}{l}\text { Flywheel material / } \\
\text { mass / dimensions }\end{array}$ & $\begin{array}{l}\mathrm{CFRP} / 4000 \mathrm{~kg} / 2 \mathrm{~m} \text { in diameter } \\
\text { and } 0.9 \mathrm{~m} \text { in height }\end{array}$ \\
\hline Thrust bearing & $\begin{array}{l}\text { Magnetic bearing composed of RE } \\
\text { high temperature superconducting } \\
\text { coils and bulks }\end{array}$ \\
\hline Radial bearing & $\begin{array}{l}\text { Active magnetic bearing using } \\
\text { magnetic levitation [Non SMB] }\end{array}$ \\
\hline
\end{tabular}

minutes), and CFRP as it was considered suitable given the large diameter and high speed rotation of the flywheel. The principal specifications of the FESS prototype are shown in Table 2, and its architecture is illustrated in Fig. 6 .

Only a limited four-year period was available for the development of the prototype and execution of demonstration tests, therefore the main focus of the development was on the SMB and the CFRP flywheel which were considered to be the key technologies in the prototype [4].

The SMB and the CFRP flywheel are described below.

\subsection{CFRP flywheel}

The energy storing flywheel in the prototype FESS had an outer diameter of $2 \mathrm{~m}$, an inner diameter of $1.4 \mathrm{~m}$ and a thickness of $0.1 \mathrm{~m}$.

The flywheel consisted of 9 laminated CFRP rings, with a diameter of $2 \mathrm{~m}$ and height of $0.9 \mathrm{~m}$.

The CFRP flywheel was designed to be able to store the target $100 \mathrm{kWh}$ when rotated at 6,000 revolutions per minute.

The features of the CFRP flywheel are described below.

A specialized manufacturing process explained below, was applied. Carbon fiber is arranged in the circumferential direction and also in the radial direction so that the necessary strength may be obtained against the centrifugal force which is generated when the CFRP flywheel is rotated at 6,000 revolutions per minute. The CFRP flywheel with a diameter of $2 \mathrm{~m}$ was finally built with epoxy resin making it the largest of its kind in the world [5].

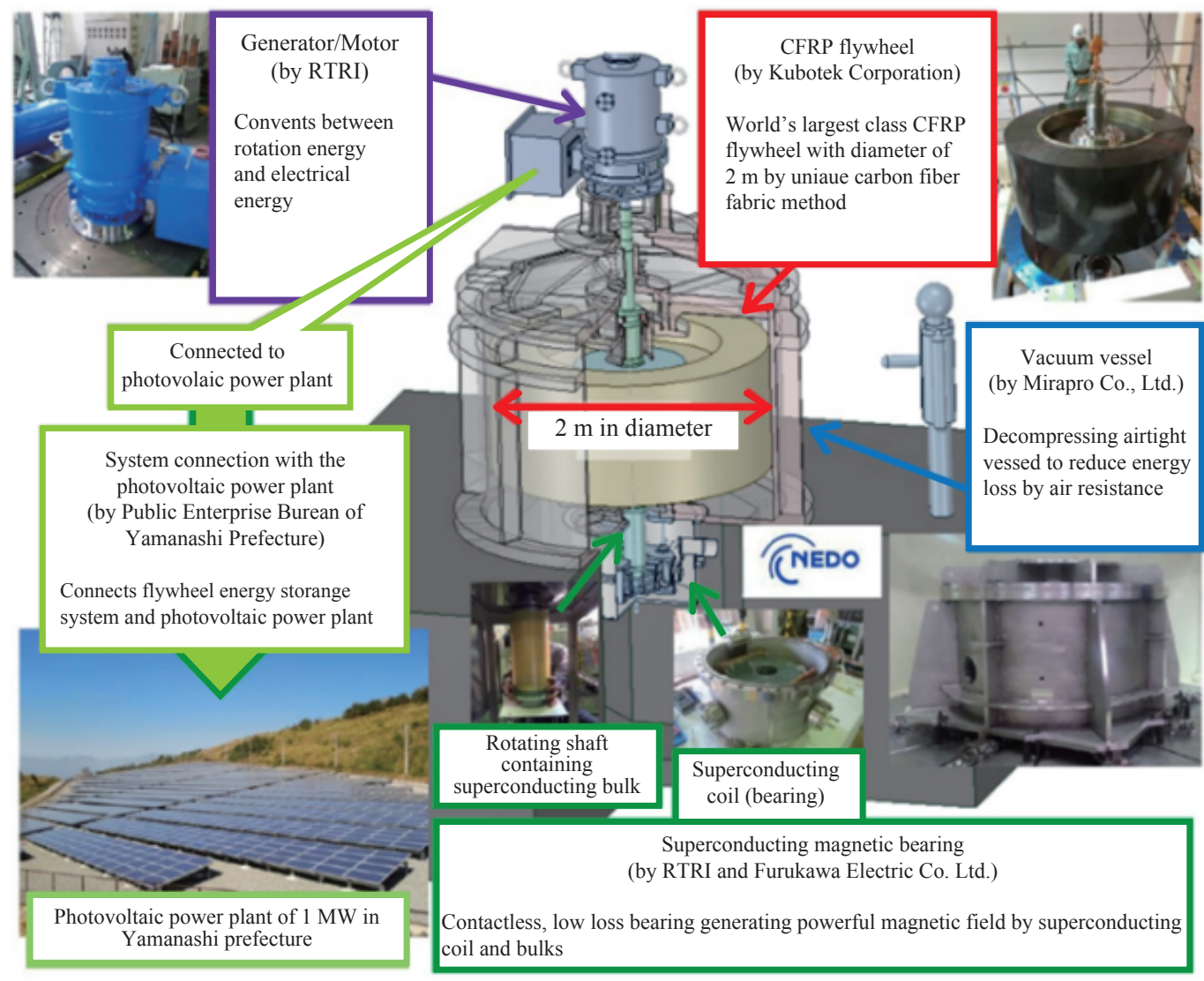

Fig. 6 Prototype FESS system configuration 
The design of the CFRP flywheel allows energy storage capacity to be determined at will simply by changing the number of laminated rings.

The generator motor rotary shaft installed at atmosphere and the flywheel rotary shaft rotating at high speed in the vacuum container were directly connected through the world's highest-speed rotating vacuum seal, which was developed by the Railway Technical Research Institute. The connection transmits the necessary power for the flywheel to rotate [6].

\subsection{SMB (Superconducting Magnetic Bearing)}

With the FESS prototype, a flywheel rotor of $4,000 \mathrm{~kg}$ $(39.2 \mathrm{kN})$ was levitated $20 \mathrm{~mm}$ by a strong magnetic repulsion power generated by a small superconducting magnetic bearing, allowing contactless support.

A magnetic field analysis result for the SMB of the FESS prototype is given in Fig. 7 [7].

The high temperature superconducting coil generating the strong magnetic field (hereinafter, HTS coil) and the high temperature superconducting bulk body (hereinafter, HTS bulk body) are cooled down to a fixed temperature, and an electric current is sent to the HTS coil to magnetize it. Then a shelter electric current is generated in the HTS bulk denying the magnetization of the HTS coil, creating magnetic repulsion between the HTS coil and the HTS bulk body.

The role of the SMB is to make the flywheel levitate stably without mechanical loss, using the above-mentioned mechanism. The HTS bulk body is made by arranging large disk-shape single crystals produced by QMG [8].

The crystals are made from the same second generation high temperature superconducting substance as for HTS coil wire.

The HTS coils in the FESS prototype consist of 5 laminated coil units made by winding tape-like high temperature superconducting $6 \mathrm{~mm}$ wide and $0.1 \mathrm{~mm}$ thick wires into coils which have an outer diameter of $260 \mathrm{~mm}$ and inner diameter of $120 \mathrm{~mm}$. Table 3 gives the detailed specifications. The appearance of the SMB stator coil unit is shown in Fig. 8.

The HTS bulk body (SMB rotor) was made by laminating one bulk body with a diameter of $140 \mathrm{~mm}$ and depth of $20 \mathrm{~mm}$ and two bulk bodies with a diameter of $90 \mathrm{~mm}$ and depth of $20 \mathrm{~mm}$.

The main role of the 140 mm-diameter HTS bulk body is to generate the levitation force required to support the flywheel body including the rotation shaft, while the main
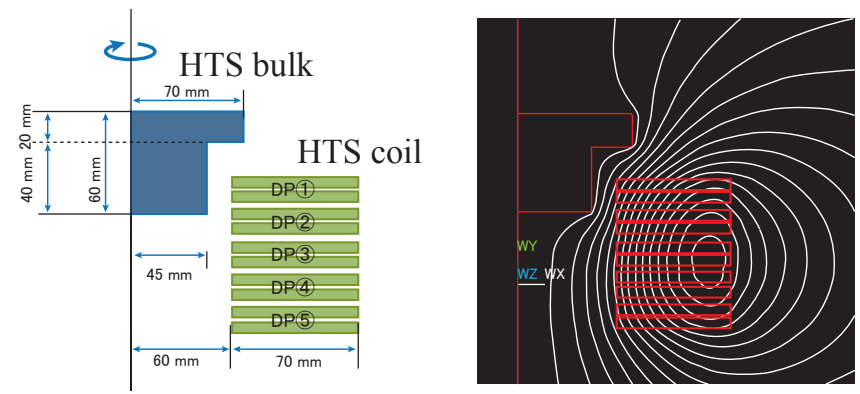

Fig. 7 Magnetic field analysis for the SMB
Table 3 Specifications of HTS coil

\begin{tabular}{|c|c|}
\hline Item & $\begin{array}{c}\text { Specification } \\
\text { Wire }\end{array}$ \\
\hline Width tape & $6 \mathrm{~mm}$ \\
\hline Thickness of tape & $0.1 \mathrm{~mm}$ \\
\hline Inner diameter & $120 \mathrm{~mm}$ \\
\hline Outer diameter & $260 \mathrm{~mm}$ \\
\hline Height of the coil & $17.6 \mathrm{~mm}$ \\
\hline
\end{tabular}

role of the $90 \mathrm{~mm}$-diameter HTS bulk body is to generate the force to guide this axis around the rotational center.

The relationship between the coil current and the levitation force of the developed SMB is indicated in Fig. 9 [9].

It was found out that the levitation force of $39.2 \mathrm{kN}$ necessary to support the flywheel body can be achieved when HTS coil of the SMB is cooled to below $50 \mathrm{~K}$ (minus $223^{\circ} \mathrm{C}$ ) through refrigeration and with an electric current of about $80 \mathrm{~A}$ sent to the superconducting coil.

The SMB was also designed so that the liquid cryogen, such as liquid-nitrogen, becomes unnecessary for maintaining the required temperature for functioning the SMB. This is because by using the HTS wire, the required temperature can be achieved by conduction cooling through the refrigerator, which facilitates the use of the SMB.

The measured power consumption of the refrigerator

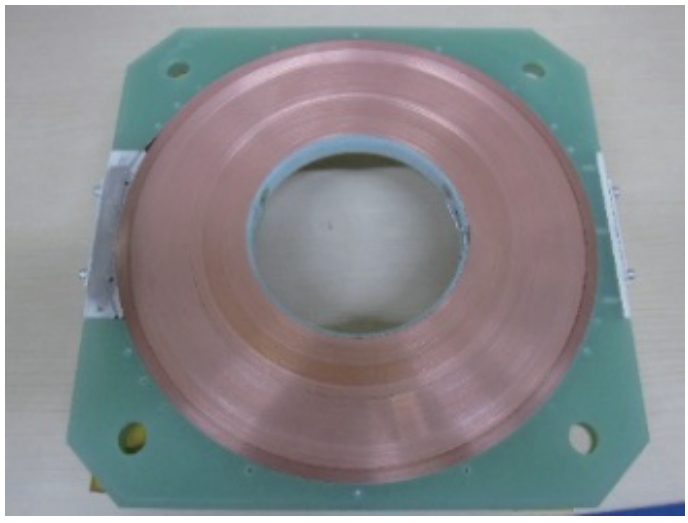

Fig. 8 The appearance of the SMB stator coil unit

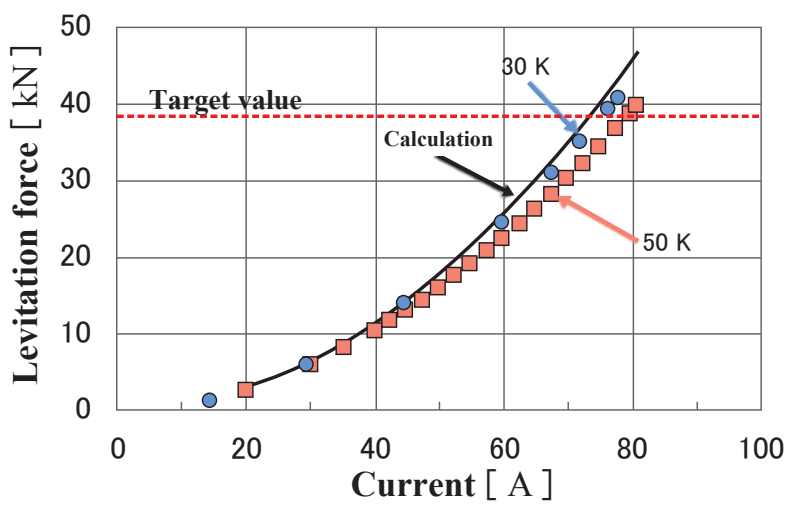

Fig. 9 Relationship between coil excitation current and levitation force 


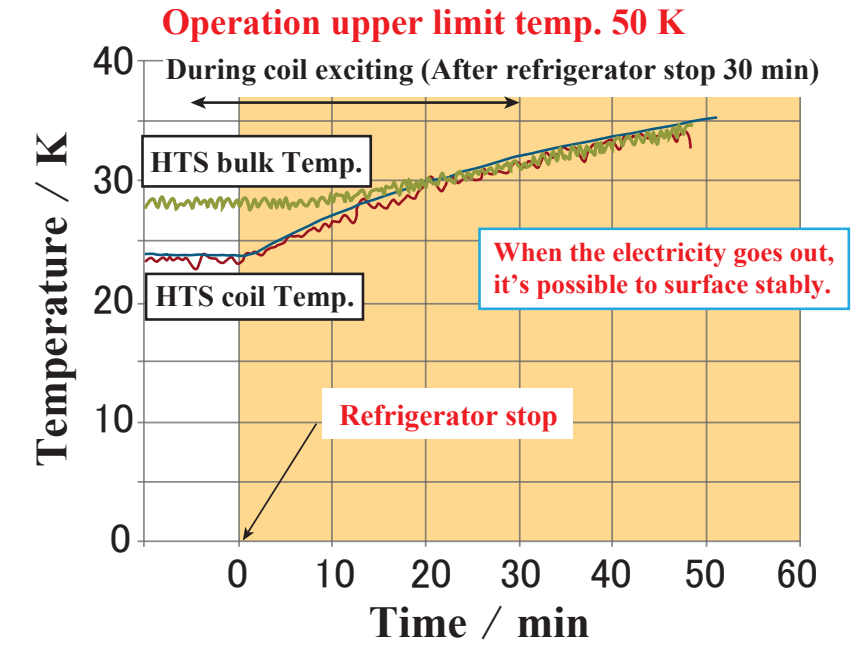

Fig. 10 Characteristics of the rise in temperature following loss of refrigeration

when the SMB is operated at $20 \mathrm{~K}$ (minus $253^{\circ} \mathrm{C}$ ), was 2.9 $\mathrm{kW}$, confirming that power consumption was below $1 \%$ of $300 \mathrm{~kW}$, the output of the prototype.

When the SMB is operated at $50 \mathrm{~K}$ (minus $223^{\circ} \mathrm{C}$ ), the heat load decreases in proportion to the rise in operating temperature. In this case the power consumption of the refrigerator is estimated to be $0.9 \mathrm{~kW}$, and accordingly the ratio of the power consumption to the output of the prototype is smaller.

The design of the SMB is such that even when the refrigerator stops, the flywheel can be maintained in a stable levitated position for 30 minutes which is the time required for the flywheel circulating at high speed to stop safely. This is achieved by insulating the cryostat so that the rise in temperature of the HTS coil and the HTS bulk body is restrained.

In addition, the SMB was equipped with an exclusive UPS power source, allowing the prototype to continue working for 1 hour, even in the event of a power cut.

The characteristics of the increase in temperature of the HTS coil and the HTS bulk body when refrigeration was stopped, are indicated in Fig. 10.

Figure 10 shows that 30 minutes after refrigeration ceases, the temperature of both the HTS coil and the HTS bulk body is $33 \mathrm{~K}$, which explains why the wheel continues to be supported because the maximum admissible operat- ing temperature is below $50 \mathrm{~K}$.

These tests also made it possible to confirm that it takes 148 minutes for the temperature to rise to $50 \mathrm{~K}$, which is the allowable upper limit temperature after refrigeration stops, validating the safety of the design for maintaining the prototype FESS's SMB at a low enough temperature [10].

\section{Reliability test results for the FESS prototype}

The FESS prototype was installed at demonstration test facilities next to a photovoltaic power plant in Komekurayama in Yamanashi Prefecture. Grid connection test to confirm the moderating effect of the system on power output generated by sunlight etc. began in September 2015 by connecting the prototype to a solar power plant with an electric output of $1 \mathrm{MW}$. An example of the test results are shown in Fig. 11.

The upper orange curve indicates that solar panel power output fluctuates over time by several hundred $\mathrm{kW}$.

In response to solar panel output fluctuations the prototype FESS charged/discharged the power, as indicated by the bottom green curve, while the red curve shows the nearly constant power flowing into the grid.

Figure 12 gives examples of the number of rotations and lift height control results of the SMB during the grid connection tests Fig. 12.

Figure 12 confirms in the 7 hours or so from when the test began to when it ended, the repeated rise and fall in the number of rotations of the prototype FESS accompanying the battery charging and discharging cycles which followed fluctuations photovoltaic output did not influence the levitation height of the SMB, and shows that the levitation of the SMB in the control area is stable (standard value $\pm 0.5 \mathrm{~mm}$ ).

Accordingly, it was considered that the data proving the moderation effect of the prototype FESS on photovoltaic output, was obtained [11].

SMB levitation tests were conducted for more than 3,000 hours during the demonstration tests which began in September 2015, including tests with the FESS prototype in a test plant. During these experiments, no problems at all were detected with the superconducting system, and therefore it is considered that the reference data for verifying the stability of the SMB for practical use were ob-

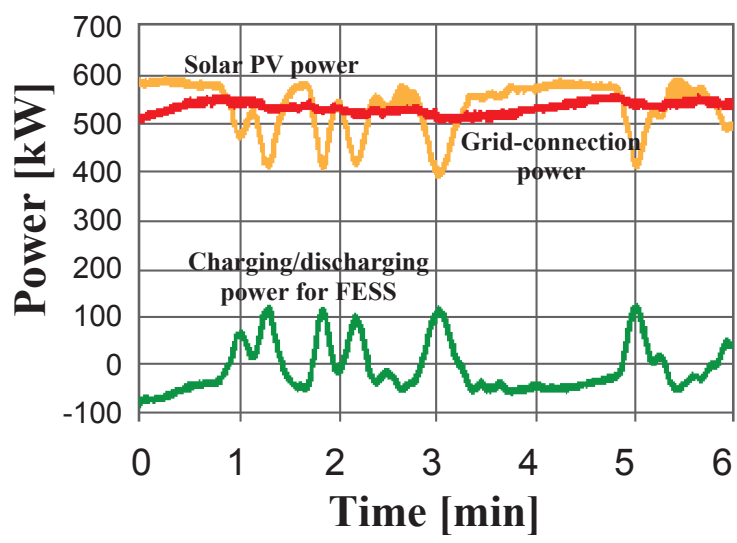

Storage system conditions

Charging/discharging power : $200 \mathrm{~kW}$

Number of revolutions : $1,000 \sim 1,800 \mathrm{rpm}$

Storage volume : $0 \sim 9.0 \mathrm{kWh}$

Fig. 11 Example of validation of Solar PV power smoothing effect with the FESS 


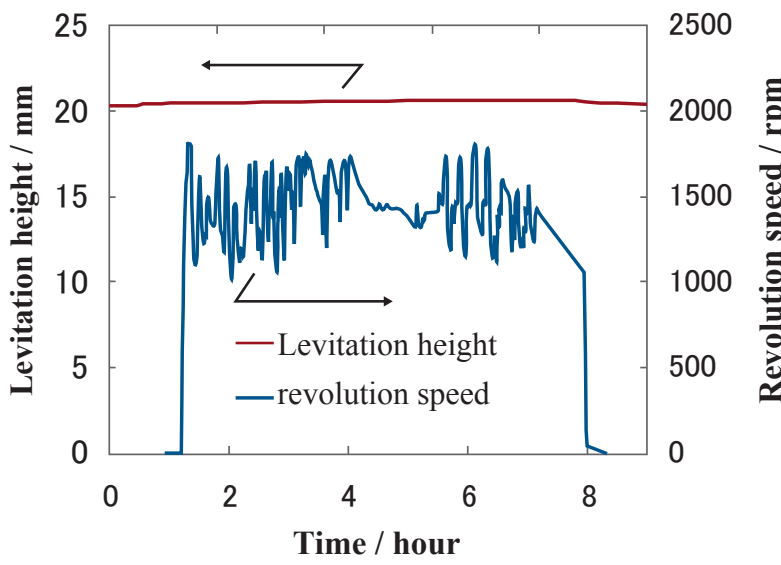

Fig. 12 Example of SMB stability during connection tests

tained.

Given the time that would have been needed to conduct tests to improve rotational speed the prototype FESS tests could only prove the system's charge capacity of 25 $\mathrm{kWh}$. Nevertheless, it was possible to prove electric power charging/discharging at a maximum output of $300 \mathrm{~kW}$.

The charge capacity of $25 \mathrm{kWh}$ proved this time is equivalent to the charge capacity of the charging equipment in conventional flywheels used on the Zushi line of the Keikyu Corporation and is considered to be a practical charge capacity for railways [12].

NEDO financial support ended at the end of February 2016 , but acceleration tests to verify the reliability and durability of the core technologies continued utilizing the prototype FESS.

Assuming that the operating life of SMB of core technology is 20 years, acceleration tests were conducted, repeating excitation and degaussing to 100 times the normal equivalent and at 5 times the normal intensity and acceleration tests repeating cooling and heating cycles to 24 times the normal equivalent and to 1.2 times the normal intensity.

Ic and n-values of 5 HTS coils constituting the SMB, measured after the above-mentioned acceleration tests compared with factory door values, are shown in Fig. 13.

Here, Ic is the highest current able to maintain a superconducting state, and the n-value is the evaluation index based on the special quality of electric voltage gener-

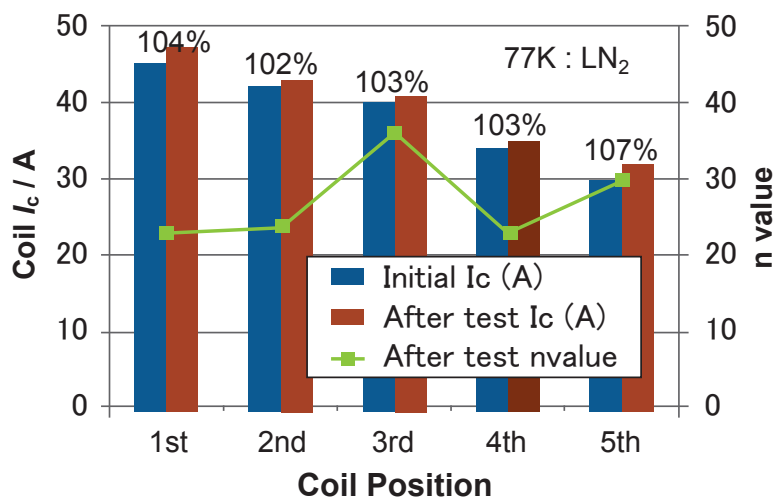

Fig. 13 Results of reliability tests to determine serviceable life of HTS coils ated during the transition from a superconducting state to normal conduction.

By rule of thumb, it is considered that an HTS coil had deteriorated in the test when the n-value fell below 20 and Ic diminished to below $30 \mathrm{~A}$.

Figure 13 shows that the significant difference in Ic is invisible before and after the acceleration test on each coil and the $\mathrm{n}$-values were all over 20.

Accordingly, the HTS coil did not deteriorate during these tests.

These results demonstrate the high reliability of a superconducting magnetic bearing as a core technology throughout the expected operating life of 20 years [13].

\section{Developing the technology for application to rail- ways}

Based on results from the Komekurayama's demonstration tests, namely "confirmation of the validity the superconducting flywheel energy storage technique for short repetitive cycles," the Railway Technical Research Institute considered that this technology could have many applications including acting as an effective countermeasure against loss of regenerative electric power from the railways, against voltage drops, to ensure more stable supply of power in overhead trolley wires, against fluctuations in electric load due to sudden power variations in substations, and as an urgent run (BCP) measure to the nearest station when power is lost.

Based on the knowledge obtained from the Komekurayama power plant in Yamanashi Prefecture, the Railway Technical Research Institute is planning to continue work on the design of a FESS for the railways, exploiting the high degree of freedom in design which allows energy storage capacity and output of the FESS to be set independently.

\section{Conclusions}

This paper describes the principles underlying and main features of a FESS built with the superconducting magnetic bearing developed by the Railway Technical Research Institute as a core technology, results of the demonstration tests conducted in Komekurayama, and application of this new mechanical electric energy storage system to the railways.

The development of this prototype FESS was selected among 150 projects, as one of the "Top 10 Innovations" at the 2015 General Assembly of the "Innovation for a Cool Earth Forum' (ICEF) along with MIRAI of Toyota [14].

This prize demonstrates that this new power storage technology has garnered international interest.

\section{Acknowledgement}

The present research and development was carried out by the Railway Technical Research Institute, KUBOTEK Corp., Furukawa Electric Co., Ltd., Mirapro Co., Ltd. and the Yamanashi Prefecture Bureau of Public Enterprise 
with the financial support of NEDO, for "development of the next generation flywheel energy storage systems."

The authors would also like to express their gratitude for the cooperation from other companies including Nippon Koei Co., Ltd., Eagle Industry Co., Ltd. and Matsuikozai, Inc. group who also contributed to the development of the prototype FESS.

\section{References}

[1] http://www.rtri.or.jp/press/pdf/20150903-1.pdf

[2] Nagashima, Ken., Seino, Hiroshi., Miyazaki, Yoshiki., Arai, Yuuki., Sakai, Naomichi. and Murakami, Masato., "Loading force density of a superconducting magnetic bearing using superconducting bulk body and superconducting coils," RTRI Report, Vol.21, No.9, pp.29-34, 2007 (in Japanese).

[3] http://www.rtri.or.jp/press/2011/20110606.html

[4] Hasegawa, Hitoshi., Matsue, Hitoshi., Nagashima, Ken., and Yamashita, Tomohisa., "Development of superconducting flywheel energy storage systems for demonstrations," RTRI Report, Vol.29, No.11, pp.4146, 2014 (in Japanese).

[5] http://www.kubotek.com/info/pdf/news/2015/CFRP_flywheel_nr_150202.pdf

[6] http://www.rtri.or.jp/press/pdf/20141031.pdf

[7] Mukoyama, Shinichi., Matsuoka, Taro. and Kasahara, Hajime., Furukawa, Makoto., Miyazaki, Yoshiki., Arai, Yuuki. and Yoshizawa, Keisuke., "Development of superconducting magnetic bearing for superconducting flywheel energy storage systems," 2014 year autumn Cryogenics engineering meeting lecture outline collection, Vol.90, p.89, 2014 (in Japanese).

[8] Teshima, Eiichi. and Morita, Mitsuru., "Development status of the performance and RE system hot superconducting bulk material technological improvement advances," Cryogenics engineering, Vol.46, pp.73-80, 2011 (in Japanese).

[9] Furukawa, Makoto., Matsuoka, Taro. and Kasahara, Hajime., Yamashita, Tomohisa., Arai, Yuuki., Mizuno, Katsutoshi. and Yoshizawa, Keisuke., "Development $\mathrm{RE}$ coil design of superconducting magnetic bearing for superconducting flywheel energy storage systems," 2014 year autumn Cryogenics engineering meeting lecture outline collection, Vol.90, p.90, 2014 (in Japanese).

[10]Nakao, Kengo., Matsuoka, Taro., Furukawa, Makoto., Yamashita, Tomohisa., Miyazaki, Yoshiki. and Mizuno, Katsutoshi., "The inspection test outcome which assumed developing-load bearing testing and the time of abnormality of a superconducting magnetic bearing for flywheel energy storage systems," 2015 year spring Cryogenics engineering meeting lecture outline collection, Vol.91, p.13, 2015 (in Japanese).

[11] Yamashita, Tomohisa., Ogata, Masafumi. and Nagashima, Ken., "The superconducting flywheel energy storage systems a demonstration experiment advances," Japan Railway Engineers' Association, Vol.59, No.9, pp40649-40652, 2016 (in Japanese).

[12]Akimoto, Toshiyuki. and Fujita, Takayoshi., "The application of the energy storage systems in railway supply of electric power (8)," Railway and Electric technic, Vol.25, No.5, pp63-66, 2014 (in Japanese).

[13]Nakao, Kengo., Matsuoka, Taro., Mukoyama, Shinichi., Yamashita, Tomohisa., Ogata, Masafumi. and Miyazaki, Yoshiki., "Development of a superconducting magnetic bearing (SMB) for superconducting flywheel energy storage systems - Stability inspection of SMB - 2016 year spring," 2016 year spring Cryogenics engineering meeting lecture outline collection, Vol.93, p128, 2016 (in Japanese).

[14] http://www.icef-forum.org/pastevent/outcomes/pdf/icef_ top10_4.pdf

\section{Authors}

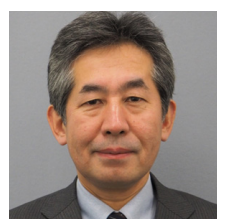

Tomohisa YAMASHITA

Senior Research Engineer, Maglev Systems Technology Division

Research Areas: Cryogenics and

Superconductivity

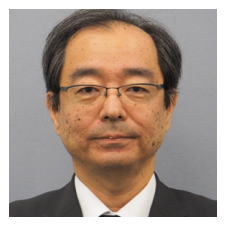

\section{Masafumi OGATA}

Laboratory Head, Cryogenic Systems

Laboratory, Maglev Systems Technology

Division

Research Areas: Cryogenics and

Superconductivity

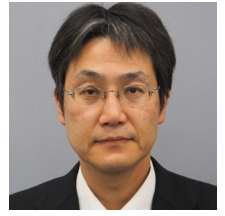

Hitoshi MATSUE

Senior Research Engineer, Cryogenic Systems Laboratory, Maglev Systems Technology Division Research Areas: Magnetic Levitation

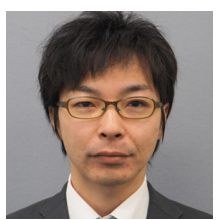

Yoshiki MIYAZAKI

Assistant Senior Research Engineer, Cryogenic Systems Laboratory, Maglev Systems Technology Division Research Areas: Cryogenics and Superconductivity

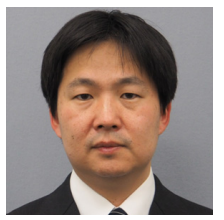

Motohiko SUGINO

Assistant Senior Research Engineer,

Cryogenic Systems Laboratory, Maglev Systems Technology Division (Present: Central Japan Railway Company) Research Areas: Cryogenics and Superconductivity

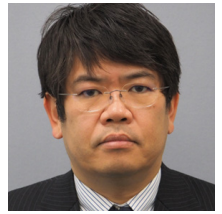

Ken NAGASHIMA, Ph.D.

Director, Maglev Systems Technology

Division

Research Areas: Cryogenics and

Superconductivity 